\title{
An analysis of grey water treatment system in the national university of Malaysia mosque
}

\begin{abstract}
This paper is trying to analysis and proposes some design of grey water system in The National University of Malaysia (UKM) mosque in order to save environment. With proper grey water treatment, UKM Mosque will contribute to save water and UKM's environment. This successful water treatment is also can be an alternative model to apply in another building. This environmental issue, especially water was realized by Universiti Kebangsaan Malaysia (UKM) by starting to be a first pioneer in Green \& Sustainability Campus in Malaysia. Although UKM is located in water-rich country, still UKM try to commit to save environment as well as manage its environment aspect. The usage of water in UKM itself is categorized in high level. UKM have around 20.000 students and most of them are dwelling in campus. For big campus like this, UKM had one main Mosque which accommodates some daily worship of Moslem as the majority one. For activities like ablution, washing and bathing, UKM Mosque had produce quite big amount of grey water. Grey water itself is residual water that still fresh and can be recycled for some purposes such as landscape irrigation and cleaning service. One alternative method to treats the grey water is by the usage of filter wells.
\end{abstract}

Keyword: Filter wells; Grey water; UKM mosque 